\title{
ROLE OF EFFECTIVE DIVERSITY MANAGEMENT PRACTICES TOWARDS PROJECT SUCCESS
}

\author{
SANA KARIM \\ Riphah International University, Islamabad, Pakistan
}

\begin{abstract}
This study evaluated the role of effective diversity management practices towards the success of the project in both government and private sector organizations of Pakistan, with the mediating role of project efficiency. Data were collected from 100 respondents working in government/private sector organizations in Pakistan; using questionnaires, based on 5 point likert scale. The results of this study confirmed that there is a positive relation between diversity management practices and project efficiency. Also it is confirmed that the project's success and efficiency are positively linked with each other and effective diversity management practices in Pakistan do help project managers in leading the projects towards success. The study concluded that in country like Pakistan, having a masculine culture, masculinity acts as a moderator, to strengthen the relationship between project efficiency and project success. Implications and strategies to address the issues on Pakistani context are also discussed.
\end{abstract}

\section{INTRODUCTION}

According to Dulaimi and Hariz (2011) diversity plays an essential role in the overall success of the project team, however managing the diverse teams is a complex task. In this competitive business world most of the business organizations seek to make it a mainstream issue so that they can address legal obligations and complete their projects in an efficient manner (Popescu et al, 2014). Henderson and Stackman (2010) state that during past few decades, the project management field was mainly a male dominated field, however in the past decade women have significantly gained prominence as scholars, practitioners and teachers and both men and women are now redefining the overall typical image of the project manager and expanding the skills of the project managers required to function effectively in this rapidly changing technologically advanced business world.

In his study Anbari et al (2009) has found that there are numerous diverse benefits that can be attained by the project management teams while increasing the awareness and managing the diversity throughout the project. Most of the project managers have now recognized the importance of effective diversity management practices to their team members because it significantly increases the overall productivity and efficiency of the team leading to successful project (Turner et al, 2010). Rodrigues and Sbragia (2013) have explained that it is necessary for a project manager to identify and understand different types of diversity present in his or her team, so that he or she can capitalize those individual differences in order to improve the team's success. Moreover, after identifying the unique capabilities of individuals in the team, a project manager can easily encourage his/her team members to become aware of these diverse qualities and appropriately use them to accomplish team goals (Popescu et al., 2014).

As discussed above, managing the diversity efficiently helps project managers in attaining the ultimate goals of the project, while developing strong relations between the diverse team members and attaining team goals in an efficient manner. There are numerous different diversity management practices that help project managers in managing the diverse team during a certain project and to increase the productivity level of team members to attain the ultimate goals of the project collaboratively. As discussed by Ochieng and Price (2009) that there are various potential benefits that can be attained by the project managers by managing a highly diverse teams. However, there are different factors that help project managers in increasing the overall efficiency of the employees and increase their performance and productivity. Hence this research intends to evaluate the strategies and practices that can be helpful for the project managers in managing the culturally diverse teams for their projects. Also, this 
research focuses on evaluating the factors like effective flow of communication, relations between employees etc. that help project managers in increasing the overall efficiency of the employees working in team for the successful completion of the project.

The research focuses on evaluating the factors that increases the overall efficiency of the team members during projects and influence their performance and productivity. Furthermore, detailed overview of the effective management practices that can be used by the project managers to keep the team composed of diverse employees motivated for the efficient completion of the project. The major reason behind selection of this topic was the increasing importance of diverse workforce because diverse teams have enhanced innovation and creativity which occurs because of the broader range of background inherent and unique experiences of the culturally diverse team members (Shen et al., 2009).

\section{LITERATURE REVIEW}

\section{Diversity Management in Project}

Shen et al (2009) said that when we talk about project manager, first thing that comes to our mind is the captain of the ship who is going to start his journey from the very beginning. Ozbilgin and Tatli (2008) state that it all depends upon the project manager that how he leads his culturally diverse teams in order to obtain the desired outcomes for the project. Also leadership is the most essential thing for a project manager; however the leading role of the project manager is more difficult if the he has to manage culturally diverse teams for the project in regard to coding encoding of thoughts, culture, perceptions and personal attributes of the team members (Evans \& Glover, 2012). Effective diversity management practices during project require ample skills and leadership qualities (Oertig \& Buergi, 2006). The role of project manager as the leader has a great significance that further encourages team members and creates an effective working environment for them. These factors further help project teams in coping with the challenges in today's diversified global economy (Zhang et. al., 2015).

Diversity management is one of the most sensitive issues that a project manager has to deal with; however, it can be rewarding if managed successfully (Nguyen, 2015). Also, diversity can cover many issues such as educational background, lifestyle, ethnicity, age, disability and gender (Mohammed, 2008). If we talk in the context of project, diversity in team has been established to influence a broad range of vital team results. In global projects, diversity in teams can prompt the trade and giving out of different perceptions and ideas, which can develop team performance and boost work inspiration and contentment regarding work.

\section{Project Efficiency}

Spalek (2014) said that the concept of effectiveness and efficiency are generally used when evaluating different processes. While the project management can be described by different kinds of processes, the aim with this research is to explore the concepts within project management through the lens of quality management (Sundqvist et al., 2014). Hence within the field of project management (PM) the concepts of efficiency and effectiveness are commonly used, but rarely defined. Some researchers apply the concepts when describing how to improve some part of PM (Atkinson, 1999), some apply it when describing competencies for project execution (Morae \& Laurindo, 2013). In this regard Patanakul and Milosevic (2008) have explained that effectiveness is usually listed as one of the reasons for measuring maturity.

According to Chiocchio et al., (2015) efficiency of the project is the ratio that helps project managers in determining the overall relation between the outputs from a process against the resources invested into performance of this project. Efficiency of the project can be measured by the volume of outputs obtained per inputs utilized (Gido \& Clements, 2014). Chiocchio et al., (2015) have stated that in simple words if the output of the project is sufficient in comparison to inputs of the project then project efficiency will be equal to $100 \%$, whereas, if the project surpasses the expectations and appears to be more profitable than before then the efficiency will be equal to $110 \%$. Similarly, if the project is underperformed then the efficiency will be equal to 90\% (Gido \& Clements, 2014).

\section{Diversity Management in Project and Project Efficiency}

In today's dynamic business world the team members for the project come from totally diverse backgrounds which further provides numerous benefits to the project along with some challenges for the project manager (Liang \& Liu, 2007). Ruigrok et al., (2010) states that effective diversity management practices help project managers in managing culturally diverse team in an efficient manner, while avoiding any conflicts between team members and promoting effective communication among them (Dulaimi \& Hraiz, 2011). Effective diversity management practices help project managers in aligning the performances of the team members with the ultimate objectives of the project while keeping them motivated and satisfied (Jehn, 1999). Moreover, 
the increased motivation and satisfaction of project's team members will further promote positive working environment and attitudes of the team members leading to increased efficiency and productivity (Campion, 2011). In this regard, Senichev (2013) has also explained that the increased performance and productivity of the team members during project collectively contribute in increasing the overall efficiency of the project, which further helps project managers in attaining the ultimate aims and objectives of the project in an efficient manner (Gotsis \& Kortezi 2014).

Hypothesis 1. There is a positive and significant relationship between diversity management practices and project efficiency

\section{Project Success}

Bakker et al (2010) said that the project success is a core project management concept; however, there is no standardized definition of a 'project success' in the project management literature, because the success of a project is perceived differently by different success assessors. Serrador (2013) believes that the success of the project is not only meeting cost, schedule, and performance requirements; rather it requires satisfaction of more complex specifications, such as client satisfaction. In regard to the client satisfaction, Howsawi et al., (2014) have stated that the satisfaction of the client achieved along with end results, have influence on perceived success or failure of the project. As discussed above time, budget and scope of the project are crucial for the project's success; however they are necessary conditions not sufficient conditions (Shields et. al., 2010).

\section{Project Efficiency and Project Success}

The efficiency of the project is directly linked with the success and failure of the project (Serrador, 2015). If the efficiency of the project is satisfactory then the project manager would be able to obtain desired outcomes from the project. Pedro (2015) has explained that the efficiency of the project is linked with meeting the cost, time and scope goals of the project, while the success of the project depends upon the wider business and enterprise goals. In this regard Moreau (2016) has also stated that there is a general agreement that although schedule and budget performance alone are considered inadequate as measures of project success, they are still important components of the overall construct. Mir and Pinnington (2013) have explained that the efficiency of the project is crucial for the success of the project because if the project is late and over budget then it will be more difficult for it to be a business success.

\section{Hypothesis 2. There is a positive and significant relationship between project efficiency and project success}

\section{Diversity Management Practices and Project Success}

Dike (2012) said that diverse teams for the project are often acknowledged as an essential goal while developing an effective team for the project, because diverse teams for the project clearly add strengths. However, it is necessary for the project managers to manage diverse teams in an efficient manner because it presents various challenges for them, e.g. multiple viewpoints, working styles and personalities ( $\operatorname{Rad} \&$ Anantatmula, 2010). Diversity if managed properly and efficiently can significantly spark innovation, fresh thinking and creativity, because it provides a variety of new and creative ideas from different members of the team. Moreover, effective and diverse teams for the project further help project managers in increasing the overall strength of the team while compensating for the shortcomings of the team members (Pryke \& Smyth, 2012). Hence, diversity in the project teams acts majorly as a source for greater productivity and success for the project. Diversity in the project team plays a crucial role in team success (Weinstien \& Jaques, 2010).

Nancy (2014) has explained that it is necessary for the project manager to determine different types of diversity present in his or her team, the project manager is one step closer to being able to capitalize on these individual differences in hopes of improving team success. Furthermore, once the unique capabilities of each individual have been identified, a project manager is able to encourage team members to become aware of these diverse qualities and appropriately use them to achieve team goals, which further leads to successful completion of the project (Zein, 2016). There are quite a few benefits that project manager can obtain by successfully managing the diverse teams for the project (Tinnirello, 2001). Firstly, the diverse team is more apt to modify current processes to make them more efficient, which greatly increases overall productivity and quality. Secondly, teams become more effective through synergy and cooperation because team members are more equipped to communicate effectively, handle conflicts and are more respectful toward fellow team members (Bogeun, 2013). It also increases the creativity and innovation, which occurs due to the broader range of unique experiences and backgrounds inherent in team members.

Hypothesis 3. There is a positive and significant relationship between effective diversity 
management practices project success

\section{Mediating Role of Project Efficiency}

As discussed above, the efficiency of the project can be measured by the volume of outputs obtained per inputs utilized. However, the overall morale and satisfaction level of the team members during project majorly contribute to the overall efficiency of the project, because if any team member is dissatisfied he or she will have negative attitude towards the project and/or team members; which will further affect the performance and productivity of other team members adversely. Incidentally, Kliem (2013) has explained that it is necessary for the project manager to manage the project teams efficiently, while keeping them satisfied and motivated with their job. While on the other hand, positive attitude of a team member further influences the attitudes of other team members positively and additionally leads to increase in their motivation and satisfaction level (Richman, 2002). The increase in satisfaction and motivation of the team members further increases their productivity and performance during task, which ultimately leads to increase in the efficiency of the project. Hence, it can be seen that the overall efficiency and productivity of the members contribute to the increase in productivity and performance of the team on the whole, which further leads to increase in the efficiency of the project.

Hypothesis 4. Project efficiency mediates the relationship between diversity management and project success

\section{Moderating Role of Masculinity}

Binder (2012) has explained that masculinity and femininity reflect whether a certain society is predominantly male or female in terms of cultural values, gender roles and power relations. Every society consists of males and females, usually in approximately equal numbers. In masculine cultures, some occupations were structured based on genders, which means some jobs are given to males and others to females (Harmarij, 2013). There is also a stronger emphasis on achievements, growth and challenge in jobs (Loosemore, 2003). In these cultures, people emphasize job performance more than individual interests. Additionally, people prefer to receive money, titles or other materialistic or status-oriented rewards (Zein, 2016). On the contrary, in feminine cultures, good working conditions and job satisfaction are preferred. Meaningful rewards are leisure time, improved benefits or symbolic rewards. In this regard, Binder (2012) has explained that masculinity stresses upon growth challenge and achievements in the job which further leads to increase in the overall efficiency of the employees, ultimately increasing the efficiency of the project.

Hypothesis 5. Masculinity moderates the
relationship between project efficiency
and project success by strengthening the
relationship

FRAMEWORK FIGURE 1

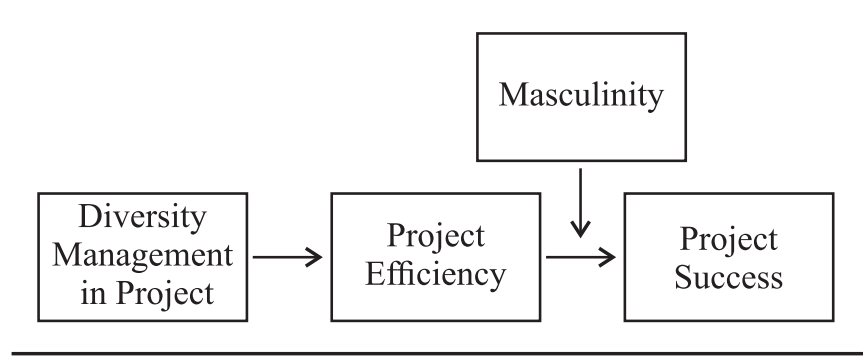

\section{RESEARCH METHODOLOGY}

The purpose of the study is to examine the impact of diversity management on project success mediated by project efficiency, with the moderating impact of masculinity. It's a cross-sectional study. Data were collected using questionnaire method. Sample was drawn using convenient sampling technique due to the time and budget constraints. Sample size of 100 employees from project based organizations across Rawalpindi, Islamabad region. Within these organizations, the employees were selected on the basis of personal contact and relevancy to the topic. Most of the participants were working in teams. The questionnaires were distributed among 140 employees in different project based organizations, out which 128 were returned and only 100 usable. The response rate was $92 \%$. Already developed questionnaires were used, on five point Likert scale from $1=$ strongly Disagree to 5 = Strongly Agree.

\section{RESULTS}

\section{Correlation Analysis}

To test the research model, a survey was conducted, identified from a list of participants selected. The sample size was 100 . Within these organizations, the employees were selected on the basis of personal contact and relevancy to the topic as they all were working in different sectors; adhere to project completion and success. $57 \%$ of the respondents of this research were male, while $43 \%$ were female. 
Furthermore $19 \%$ of the respondents were between age group of $18-30,16 \%$ were between $31-40,37 \%$ were between $41-50,24 \%$ were 51-60, while only $4 \%$ i.e. 4 respondents were above the age of 60 . With regard to the qualification of the respondents $6 \%$ respondents had metric education, $2 \%$ respondents were intermediate, $22 \%$ of the respondents were holding bachelor's degree, $58 \%$ of the respondents were master degree holder and $12 \%$ were PhDs. Moreover, majority of the respondents were from private organizations and $32 \%$ were from government organization.

TABLE 1

Correlation Analysis

\begin{tabular}{lllll}
\hline & 1 & 2 & 3 & 4 \\
\hline $\begin{array}{l}\text { Diversity } \\
\text { Management }\end{array}$ & 1 & & & \\
$\begin{array}{l}\text { Project } \\
\text { Efficiency }\end{array}$ & .032 & 1 & & \\
Masculinity & .209 & .086 & 1 & \\
Project Success & -.002 & -.134 & -.117 & 1 \\
$* p=0.05 * p=0.01$ & & &
\end{tabular}

TABLE 2

Mediated Regression Analysis

\begin{tabular}{lccc}
\hline Predictors & \multicolumn{3}{c}{ Outcome } \\
& \multicolumn{3}{c}{ Project Success } \\
& $\boldsymbol{\beta}$ & $\mathbf{R}^{\mathbf{2}}$ & $\Delta \mathbf{R}^{\mathbf{2}}$ \\
\hline $\begin{array}{l}\text { Step 1 } \\
\text { Control Variables }\end{array}$ & & .001 & \\
$\begin{array}{l}\text { Step 2 } \\
\text { Project Efficiency }\end{array}$ & .086 & .007 & .007 \\
$\begin{array}{l}\text { Step 3 } \\
\text { Diversity } \\
\text { Management }\end{array}$ & .209 & $.044^{* *}$ & $.044^{* *}$ \\
\hline$* p=0.05^{* *} p=0.01$ & & &
\end{tabular}

TABLE 3

Moderated Regression Analysis

\begin{tabular}{lccc}
\hline Predictors & \multicolumn{3}{c}{ Outcome } \\
& \multicolumn{3}{c}{ Project Success } \\
& $\boldsymbol{\beta}$ & $\mathbf{R}^{2}$ & $\Delta \mathbf{R}^{2}$ \\
\hline
\end{tabular}

\section{Step 1}

Control Variables

.157

Step 2

\begin{tabular}{lccc} 
Project Efficiency & -.059 & .196 & .039 \\
Masculinity & $.191 * *$ & & \\
Step 3 & & & \\
PE*M & $0.366^{* * *}$ & $.271^{* * *}$ & $0.75^{* * *}$ \\
\hline$* p=0.05, * * p=0.01, * * * p=.001$ &
\end{tabular}

Reliability should be (0.7 or above 0.7$)$ and Masculinity shows higher reliability (.75) which means it has a strong impact on both IV and DV respectively. Diversity management shows strong or moderate reliability (.68). Project efficiency shows less reliability than the given reliability value (.60), but within acceptable range. Project success also shows less reliability than expected value which mean that DV of research is not strong but it takes effect on it as the IV and moderator of research are strong enough.

\section{Regression Analysis}

The first hypothesis of this research was that there is a positive and significant relationship between diversity management practices and project efficiency and the results of the mediated regression analysis (table 2) show that the diversity has positive relationship with project efficiency having $\beta$ value of .032 , but the significance value of $\mathrm{P}$ is greater than 0.05 , thus leading to the rejection of hypothesis one. $\mathrm{R}^{2}$ and $\Delta \mathrm{R}^{2}$ were also observed at $.947^{* * *}$. The second hypothesis of this research was that the project success and project efficiency are positively linked with each other and the results of the regression analysis show that the Project efficiency has a positive relationship with Project Success having $\beta$ value of .086 but the significance level does not fulfill the requirements that $\mathrm{p}$ value should be $\leq 0.05$ which is acceptable range. $\mathrm{R}^{2}$ and $\Delta \mathrm{R}^{2}$ were also observed at .007 . Therefore, hypothesis two had been rejected as well.

The third hypothesis of this research was that there is a positive and significant relationship between effective diversity management practices and project success. Results of the regression analysis show that Effective diversity management positively help project managers in leading project towards success having $\beta$ value of $0.366^{* * *}$ where value of $p$ is .000 which fulfills the requirements that $\mathrm{P}$ values should be less than 0.05 . $\mathrm{R}^{2}$ and $\Delta \mathrm{R}^{2}$ were also observed at $.271^{* * *}$ and $.075^{* * *}$ respectively. Thus, the hypothesis is accepted. Fourth hypothesis of this research was that the project Efficiency plays mediating role between Diversity Management and Project Success and the results of the regression analysis show that the project efficiency does not mediate the relationship between diversity management and project success having $\beta$ value of .086 but the significance value does not fulfill the requirements that $\mathrm{p}$ value should be $\leq 0.05$, which is acceptable range. $R^{2}$ and $\Delta R^{2}$ were also observed at .007 . Thus the hypothesis is not supported. Fifth hypothesis stated that the masculinity plays a moderating role between Project Efficiency and Project Success, i.e. it strengthens the relationship. Moderation 
analysis results (table 3) indicate that the impact of interaction term, i.e. Project efficiency and masculinity ( $\left.\mathrm{PE}^{*} \mathrm{M}\right)$ is significant, with the change in $\mathrm{R}^{2}$ at .075 , therefore, this leads to the acceptance of the moderation hypothesis.

\section{DISCUSSION}

The main objective of this paper was to evaluate the role of effective diversity management practices towards the success of the project. After obtaining and analyzing the data through questionnaires from the respondents, it is evident that effective diversity management practices do contribute to the overall success of the project. The hypothesis one of the research was that there is a positive and significant relationship between diversity management practices and project efficiency and the results of regression analysis show that there is no direct relation between effective diversity management practices and the success of the project. Also the significance value does not fulfill the requirements and the hypothesis is rejected. Hence, it can be stated that in business organizations there is diversity in the workforce in Pakistan, which present numerous challenges to the project managers while handling the diverse team, however, it does not significantly help project managers in completing the projects efficiently. In this regard, the results of the study show that effective management of diverse project teams do not ensure overall project's efficiency; however, it does have a positive influence on the success of the project.

The second hypothesis of this research was that there is positive link between the efficiency and the success of the project, which has been rejected in this study. In this regard, the regression analysis has shown that efficiency and success of the project are not linked with each other, with significance value $\mathrm{P}<.05$, thus the hypothesis is rejected. The reviewed literature shows that if the overall efficiency of the project team is higher during the project then it will surely help project manager in completing the project in effective and efficient manner. While on the other hand, if the efficiency of the project team is not satisfactory during project, then this will have negative impacts on the success of the project. While the results of this research show that in Pakistan, the overall efficiency of the project is not linked with its success, hence research rejects the hypothesis. The third hypothesis of this research was whether effective diversity management practices help project managers in leading project towards success. The results of the study show that effective diversity management practices do help project managers in leading the project towards success, because it helps them in maintaining or enhancing the overall satisfaction and morale of the team members during project, which further increases their efficiency and productivity leading project towards success. Hence the hypothesis has been accepted.

Fourth hypothesis of this research was to determine if project efficiency mediates relationship between Diversity Management and Project Success. The results of the mediated regression analysis show that the overall efficiency of the project does not mediate the relation between the diversity management practices and project success because diversity management practices enhance the overall efficiency of the members in project team, which further increases the overall efficiency of the project teams leading projects towards success. Also the reviewed literature of the research shows that masculinity stresses upon growth challenge and achievements in the job which further leads to increase in the overall efficiency of the employees, ultimately increasing the efficiency of the project. The results of the moderated regression analysis indicate that masculinity does moderate the relation between project efficiency and project success, i.e. it strengthens the relationship between the two. In this regard the reviewed literature has showed that in such business environments there is a stronger emphasis on the growth, achievements and challenges in job and employee focus on job performance instead of individual interests.

\section{CONCLUSION}

The study attempted to explore the link between diversity management and the project success, with the mediating role of project efficiency and masculinity as the moderator. The data were collected from the project based organizations in Rawalpindi Islamabad region. The results of the study indicate that diversity management does have a significant and positive relationship with the project success and also has a positive relationship with the project success. Although, project efficiency does lead to the overall success of the project, it hardly mediates the relationship between the diversity management and the project success. As for masculinity, the results posited that it does moderate the relationship between project efficiency and success, i.e. incorporating masculinity as the moderator among the two further strengthens the relationship.

\section{Implications for Mangers}

The study has implications for the project managers to ensure project success. It can be stated that it is necessary for the project managers to determine the needs and wants of teams working under their supervision in order to manager and avails benefits from diverse teams of the organization. Also the project managers 
must employ effective diversity management practices while keeping the overall satisfaction and morale of the employees high because this will help them in increasing the overall efficiency of the project team which further leads a project towards success. Hence, in order to make project successful and to increase project's efficiency, the managers need to give value to the contribution made by teams in the wellbeing of the organization.

\section{Limitations}

Every research has certain limitation, so the present study isn't any different. One of the major limitations of this research was that the data was obtained from questionnaire only making it dependent upon single source. This might have led to biased responses from the respondents. Because the major limitation of questionnaire method is that sometime the respondents do not take interest in filling the questionnaire and they just fill out the questionnaire quickly without paying proper attention to the questions. This further leads to lack of validity and reliability. Likewise, the data was collected only from Twin cities area, causing the generalizability issues. Another major limitation to this study was small sample size due to the lack of time and this was the major reason that the researcher had selected the convenience sampling method as well.

\section{Recommendations for Future Research}

Although, the objectives of this research have been attained, there are still factors that could be incorporated to make the study more comprehensive. Incorporating more relevant variables as antecedents of projects success, can further help clarify the relationship. Similarly, this study focuses on studying one of the many antecedents of the project success; it can be taken a step ahead, by adding and evaluating the outcomes of the project success on overall employee and the organizational performance.

\section{REFERENCES}

Anbari, F. T., Khilkhanova, E., Romanova, M., \& Umpleby, S. (2004). Managing cultural differences in international projects. Journal of International Business and Economics, 2(1), 267-274.

Atkinson, R. (1999). Project management: cost, time and quality, two best guesses and a phenomenon, its time to accept other success criteria. International Journal of Project Management, 17(6), 337-342.

De Bakker, K., Boonstra, A., \& Wortmann, H. (2010). Does risk management contribute to IT project success? A meta-analysis of empirical evidence. International Journal of Project Management,

$$
\text { 28(5), 493-503. }
$$

Binder, J. (2016). Global project management: communication, collaboration and management across borders. CRC Press.

Bojeun, M. C. (2013). Program Management Leadership: Creating Successful Team Dynamics. CRC Press.

Chiocchio, F., Kelloway, E. K., \& Hobbs, B. (Eds.). (2015). The psychology and management of project teams. Oxford University Press.

Campion, M. M. (2011). The Relationship Between Diversity and Performance in Major League Baseball Teams: Conflict's Mediating Effect.

Dulaimi, M., \& Hariz, A. (2011). The impact of cultural diversity on the effectiveness of construction project teams. Engineering Project Organization Journal, 1(4), 213-221.

Evans, C., \& Glover, J. (2012). Diversity Management Change Projects: In Need of Alternative Conceptual Approaches?. Journal of Technology Management \& Innovation, 07(3), 12-21.

Gido, J., \& Clements, J. P. (2014). Successful project management. Nelson Education, 5th edition, p5.

Gotsis, G., \& Kortezi, Z. (2014). Critical Studies in Diversity Management Literature: A Review and Synthesis. Springer, 2nd edition, p28.

Howsawi, E., Eager, D., Bagia, R., \& Niebecker, K. (2014). The four-level project success framework: application and assessment. Organisational Project Management, 1(1), 1-14.

Hermarij, J. (2013). Better Practices of Project Management based on IPMA competences. Van Haren. 3rd edition, p126

Henderson, L. S., \& Stackman, R. W. (2010). An exploratory study of gender in project management: Interrelationships with role, location, technology, and project cost. Project Management Journal, 41(5), 37-55.

Jehn, K. (1999). Workplace Diversity, Conflict and Productivity: Managing in the 21st Century. George Harvey Program on Redefining Diversity. Vol 1, p87.

Liang, T. P., Liu, C. C., Lin, T. M., \& Lin, B. (2007). Effect of team diversity on software project performance. Industrial Management \& Data Systems,107(5), 636-653.

Loosemore, M. (2003). Essentials of construction project management. UNSW Press. 1st edition, p54.

Mohammed, U. K., White, G. R., \& Prabhakar, G. P. (2009). Culture and conflict management style of international project managers. International Journal of Business and Management, 3(5), 3-11.

de Oliveira Moraes, R., \& Barbin Laurindo, F. J. (2013). Maturity and Performance in Information Technology Project Management. Journal of 
Technology Management \& Innovation, 8, 3-3.

Mir, F. A., \& Pinnington, A. H. (2014). Exploring the value of project management: linking project management performance and project success. International Journal of Project Management, 32(2), 202-217.

Moreau, E. M. F. (2016). Project Management for a Plant Implementation: Success or failure? The Journal of Modern Project Management, 3(3), 54-66.

Erbe, N. D. (Ed.). (2014). Approaches to managing organizational diversity and innovation. IGI Global. p83.

Ozbilgin, M., \& Tatli, A. (2008). Global diversity management: An evidence based approach. Palgrave Macmillan. p39.

Oertig, M., \& Buergi, T. (2006). The challenges of managing cross-cultural virtual project teams. Team Performance Management: An International Journal, 12(1/2), 23-30.

Patanakul, P., \& Milosevic, D. (2009). The effectiveness in managing a group of multiple projects: Factors of influence and measurement criteria. International Journal of Project Management, 27(3), 216-233.

Pasian, M. B. (Ed.). (2015). Designs, Methods and Practices for Research of Project Management. Gower Publishing, Ltd. p89.

Pryke, S., \& Smyth, H. (2012). The management of complex projects: A relationship approach. John Wiley \& Sons. 1st edition, p167.

Serrador, P., \& Turner, R. (2015). The relationship between project success and project efficiency. Project Management Journal, 46(1), 30-39.

Popescu, A. D., Borca, C., Fistis, G., \& Draghici, A. (2014). Cultural diversity and differences in crosscultural project teams. Procedia Technology, 16, 525-531.

Rodrigues, I., \& Sbragia, R. (2013). The Cultural Challenges of Managing Global Project Teams: a Study of Brazilian Multinationals. Journal of Technology Management \& Innovation, 8, 4-4.

Ruigrok, W., Greve,P.,\&Engeler, M. (2011). International experiential diversity and performance at project organizations: The case of national football teams. Sport, Business and Management: An International Journal,1(3), 267-283.

Rad, P. F., \& Anantatmula, V. S. (2010). Successful project management practices. Emerald Group Publishing. 1st edition, p75.

Richman, L. (2002). Project management step-by-step.
AMACOM Div American Mgmt Assn. 1st edition, p47.

Serrador, P. (2013). The Impact of Planning on Project Success-A Literature Review. The Journal of Modern Project Management, 1(2), 32-47.

Sundqvist, E., Backlund, F., \& Chronéer, D. (2014). What is project efficiency and effectiveness?. ProcediaSocial and Behavioral Sciences, 119, 278-287.

Shen, J., Chanda, A., D'netto, B., \& Monga, M. (2009). Managing diversity through human resource management: An international perspective and conceptual framework. The International Journal of Human Resource Management, 20(2), 235-251.

Spalek, S. (2014). Finding a New Way to Increase Project Management Efficiency in Terms of Time Reduction. Inzinerine Ekonomika-Engineering Economics, 25(5), 538-548.

Senichev, V. (2013). Human resource diversity and performance within the frame of organizations, teams and individuals. Business: Theory and Practice/Verslas: Teorija ir Praktika, 14(4), 337345.

Papke-Shields, K. E., Beise, C., \& Quan, J. (2010). Do project managers practice what they preach, and does it matter to project success?. International Journal of Project Management, 28(7), 650-662.

Shen, J., Chanda, A., D'netto, B., \& Monga, M. (2009). Managing diversity through human resource management: An international perspective and conceptual framework. The International Journal of Human Resource Management, 20(2), 235-251.

Turner, R. J., Huemann, M., Anbari, F. T., \& Bredillet, C. N. (2010).Perspectives on projects. Routledge. 1 st edition, $\mathrm{p} 156$.

Tinnirello, P. C. (Ed.). (2001). New directions in project management. CRC Press. 1st edition, p27.

Weinstein, J., \& Jaques, T. (2010). Achieving project management success in the federal government. Management Concepts Inc. 1st edition, p77.

Zhang, Y., Marquis, C., Filippov, S., Haasnoot, H. J., \& Van der Steen, M. (2015). The Challenges and Enhancing Opportunities of Global Project Management: Evidence from Chinese and Dutch Cross-Cultural Project Management. Harvard Business School Organizational Behavior Unit Working Paper, (15-063).

Zein, O. (2015). Culture and Project Management: Managing Diversity in Multicultural Projects. Ashgate Publishing, Ltd. p109. 